\title{
Citizen Participation to Manage Heritage in the City of Shiraz
}

\author{
S. Koorosh Sarvarzadeh \\ Department of Social Science, \\ Islamic Azad University, Jahrom Branch, Jahrom, Iran \\ ssarvarzadeh@yahoo.com
}

\begin{abstract}
Today, citizen participation (CP) has become a global issue for mobilising untapped human resources, and it has spread across the field of Urban Heritage Conservation (UHC). This study aims to examine an indicator-based approach for the subjective evaluation of CP practice in UHC initiatives in Shiraz. It employs a questionnaire survey of 384 residents who engaged in the UHC initiatives. Finding, particularly, demonstrated that participants desire to attend a group discussion when the discussions are: respectful; possess mutual trust; respect to different points of view; equal opportunity to speak; offer common good; reciprocal dialogue; have a feedback communication.
\end{abstract}

Keywords: Citizen Participation, Urban Heritage, Evaluating, Shiraz

eISSN 2514-7528 @ 2018. The Authors. Published for AMER ABRA cE-Bs by e-International Publishing House, Ltd., UK. This is an open-access article under the CC BY-NC-ND license (http://creativecommons.org/licenses/bync-nd/4.0/). Peer-review under responsibility of AMER (Association of Malaysian Environment-Behaviour Researchers), ABRA (Association of Behavioural Researchers on Asians) and cE-Bs (Centre for EnvironmentBehaviour Studies), Faculty of Architecture, Planning \& Surveying, Universiti Teknologi MARA, Malaysia.

DOI: https://doi.org/10.21834/jabs.v3i10.299 


\subsection{Introduction}

At the last decades of the present century has already shown that there is a dramatic increase in citizen participation (CP) in the environmental decision-making process (Anuar \& Saruwono, 2013). This rise has been come both from by the public who want a larger share and role in the decisions that affect their living and by agencies that recognise the importance of the absence of citizens in their decision-making process (Charnley \& Engelbert, 2005; Peerapun, 2013). It is now considered that the main objectives of urban environmental management programmes require involving all people and agencies jointly. Despite the importance of CP in the decision-making process, it is clear that what is absent is effective monitoring instrument, particularly, to evaluate $\mathrm{CP}$ practices as a quantitative measure in assistance with the mathematical method.

In recent years, Most of the historic cities in developing countries like Shiraz in Iran are faced with similar issues (Sarvarzadeh \& Abidin, 2012). On one hand, they are experiencing high development pressure and lack of concern for cultural heritage, and, on the other hand, there is less or no citizen participation in the different levels of the decision-making process in urban development and conservation (Kong \& Yeoh, 1994; Samadi \& Yunus, 2011; Steinberg, 1996).

Therefore, this study aims to set out an indicator-based approach for the subjective evaluation of citizens' participation practice and people experiences in UHC initiatives in the Cultural-historic city of Shiraz. In fact, it carried out on two levels. One, the process they attended in it including group discussions on the issues of urban conservation in their area. Second, the outcomes created through the discursive interaction. The subjective evaluation means to prepare some information on: how citizens attend in the group discussions, what people thought they had learned and what they think about the results of their participations.

\subsection{Literature Review}

A review of the literature on evaluating citizen participation processes indicates that there is a significant literature purposed to identify criteria and assign measurable (Beierle, 1999; Beierle \& Cayford, 2002; Bradbury, 1998; Charnley \& Engelbert, 2005; Chess \& Purcell, 1999; Edwards, Hindmarsh, Mercer, Bond, \& Rowland, 2008; Rowe \& Frewer, 2000, 2004) (See table 1). As a matter of fact, there have always been the main challenges to outline the appropriate criteria for conducting an evaluation process (Mannarini \& Talò, 2013). At the first time, in 1981, four major problems have been described by Rosener (1981) for conducting an evaluation process. First, the concept of participation is complicated, and it contains many values. Second, criteria that have been held are not many for judging success and failure in the exercise; third, it has been acknowledged that there are no any consensus methods that were built to evaluate criteria; lastly, the reliable measurement tools are not numerous. 
In recent years, the complexity of new evaluation frameworks has intensified due to two reasons: one, numerous criteria have been theoretically considered by researchers; second, the different tools have been experimentally used to a different method (Mannarini \& Talò, 2013). However, what appears increasingly clear that they could not be used globally, they are today's most commonly applied based on context-dependent (Dian \& Abdullah, 2013; Mannarini \& Talò, 2013; Webler \& Tuler, 2001).

This study was intended to evaluate the process and the outcomes of citizens' participation in the urban heritage conservation. It has been carried out based on the evaluation framework outlined by Rowe and Frewer (2000, 2004), Edwards et al. (2008) and exactly the resultant of Mannarini et al. (2012). However, the study justified the criteria based on context- dependent characteristics through a Semi-structured interview with groups of experts and practitioners in the city. The interview resulted that using these criteria are well suited to evaluate the process and outcomes of CP in the UHC initiatives in the city.

Table 1 shows two categories of the criteria, the process and the outcomes, used in the study which synthesises the evaluation criteria drawn from Rowe and Frewer $(2000,2004)$, Edwards et al. (2008) and Mannarini et al. (2012). Following Edwards (2008) and by Mannarini (2012), the process factor of CP was categorised into two groups. One, dialogue, which defines as the procedures of people interact with the other citizens including authorities. Second, knowledge/ understanding, which define as whatever the participant may discuss, create, build upon, innovate, and obtain in the process of the collective discussion. This type of category was inducted many evaluation studies in the last decades (Beierle \& Cayford, 2002; Rowe \& Frewer, 2000, 2004; Webler, 1995).

Table 1: Criteria of process and outcomes for evaluating CP in the UHC initiatives

\begin{tabular}{|c|c|c|c|}
\hline \multicolumn{2}{|c|}{ Criteria } & Explanation & Source \\
\hline \multirow{3}{*}{ 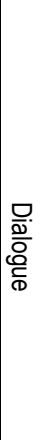 } & 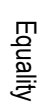 & $\begin{array}{l}\text { Participants are given equal } \\
\text { opportunities to actively } \\
\text { participate in the discussion }\end{array}$ & $\begin{array}{l}\text { Gastil (2006), Steiner et al. } \\
\text { (2003), Stromer-Galley } \\
\text { (2007), Williamson (2004) }\end{array}$ \\
\hline & 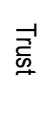 & $\begin{array}{l}\text { Participants interact in an } \\
\text { amicable atmosphere, are } \\
\text { polite and pay attention to the } \\
\text { others }\end{array}$ & $\begin{array}{l}\text { Edwards et al. (2008), } \\
\text { Innes and Booher (2003), } \\
\text { Nabatchi (2007) }\end{array}$ \\
\hline & 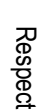 & $\begin{array}{l}\text { Dialogue is free from bias, and } \\
\text { participants are respectful of } \\
\text { each other }\end{array}$ & $\begin{array}{l}\text { Edwards et al. (2008), } \\
\text { Steiner et al. (2003) }\end{array}$ \\
\hline
\end{tabular}




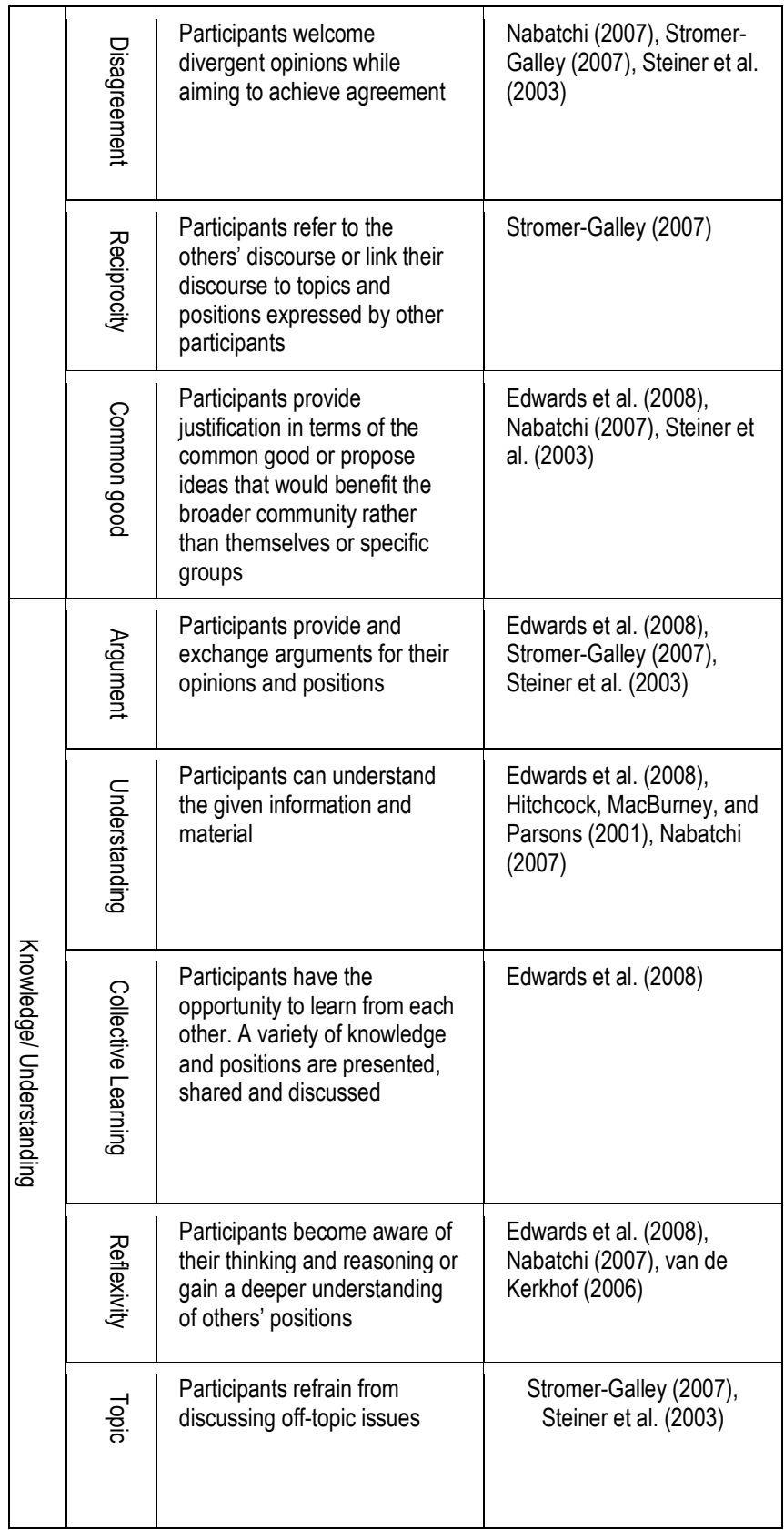

(Source: Mannarini \& Talò, 2013) 
Cultural and historic area of Shiraz, which is located in the centre of the city, was selected as a case study. Its area is about 380 hectares, equal 3 percent of the total city (see Figure 1).

It also is the initial core of the city which has passed many changes and developments during different periods. As an important epoch of the past, it is housed within itself many significant religious centres and monuments. In fact, locals recognise this area as The Old Shiraz. There are more than $\mathbf{4 0 0}$ monuments, eight historic gates and 12 quarters and 6 Cultural-Historic axes in the area which represent high cultural and environmental values of the lifestyle, social relations, customs, beliefs, history and art in the area.

In recent years, facilitator agencies were where, on one hand, they generate an appropriate motivation in the ownerships and inhabitants to take part in the urban planning and conservation initiatives. On the other hand, they possess the professional potentials to manage issues of urban conservation between the ownerships, inhabitant and local government.

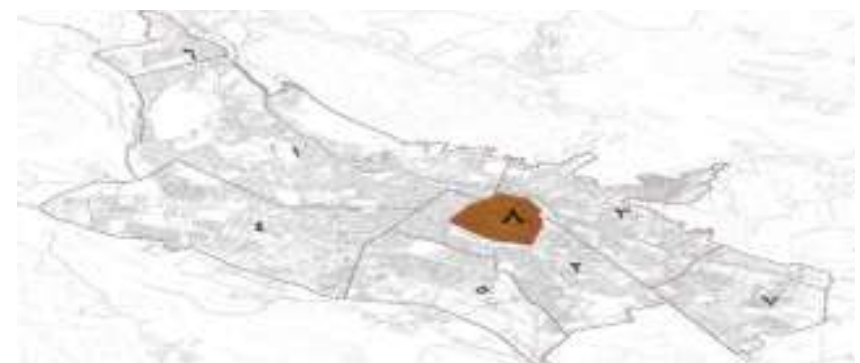

Figure 1: Situation of the Cultural-historic area of Shiraz

(Source: www.eshiraz.ir)

\subsection{Methodology}

This study intended to evaluate the features of the discursive interaction (dialogue dimension) and the cognitive processes created by people who engaged in the group discussion (knowledge/ understanding dimension) in the facilitator agencies. The evaluation criteria were extracted from the deliberation frameworks purposed by Mannarini et al. (2013). It was used to create measurement instruments for the evaluation of the participatory procedure in the facilitator bureau of UHC initiatives in Shiraz city. However, the study employed a questionnaire survey of 384 residents to evaluate the process and the outcomes of public perspective in the urban heritage conservation initiatives in the study area.

While the evaluation was concentrated on the process and outcomes, the relationships between citizens' perspective with their participation was ascertained in the study. Citizens' 
perspective was identified based on three independent variables: the place attachments, concerns to preserve cultural identity and the importance of $\mathrm{CP}$ in the UHC initiatives. It was considered so that among the experts' judegment only the citizens' perspective in the form of three above independent variables was significant to the quality of deliberation framework. This option was consistent with the primary questions underlying the experts' semi-structured interview conducted in the study: citizen's participation is good to involve in the UHC initiatives? Does the place attachment, concerns to preserve cultural identity and the importance of $\mathrm{CP}$ in the UHC initiatives influence the citizens' future behaviour? If so, the criteria evolution of the process and outcomes might be used as an indicator of the empowering potential of citizen participation in the initiatives. The researcher conducted a study to address these questions into two stages. The first purpose was to validate two evaluation instruments (process and outcomes) by a semi-structured interview. The second was to evaluate the process and the outcomes through questionnaire survey made by residents to predict their future engagement in the citizens' participation.

\subsection{Results and Discussions}

The criteria for evaluation of dialogue dimension were six: equality, trust, respect, disagreement, reciprocity, and common good. The knowledge/understanding dimension consisted of five criteria: argument, understanding, collective learning, reflexivity, and the topic. According to Mannarini (2013), three items (totally 33 items) were created for each item in the evaluation process (Table 2). These items were gone to measure based on a seven-point scale (from 1 = strongly disagree to $7=$ strongly agree) through Delphi method. According to Edwards et al. (2008) and Mannarini (2013), a four-item scale has been designed to measure the perceived outcomes obtained by the discussion. It should be mentioned that each evaluation criteria got the following item: Discourse; did the current citizen's participation practice (CPP) create new knowledge on the issue of urban conservation under the group discussion? Networks; the new communicational networks were established through current CPP? Influence; people's formulated proposals will be implemented in the area? Achievement; did the current CPP yield proposals the adequately address the issues of UHC in the area?

In the part of the analysis, the 33 evaluation items have been used for confirmatory factor analysis (CFA) for testing the study's hypothesised structure. It is considered that the analysis demonstrated that the items saturated with two dialogues and knowledge/understanding factors. It also mentioned that these did not saturate with the outcomes factors. It means that two dialogues and knowledge/understanding criteria were correlated with items, but the secondary criteria (outcomes) did not correlate with the primary one. Then, the other CFA was applied to test the hypothesised model which corroborated the 11-item scale for using in the evaluation process.

Totally, the scale consisted of 15 items. Each factor got one item, except for factors trust, disagreement, the common good and reciprocity that were composed of two items. Figure 2 illustrates the final model outlined in the evaluation process of factors. 
In the next stage, a confirmatory factor analysis (CFA) was conducted for testing the four items of outcome criteria (discourse, networks, influence, achievement). The results indicated that these criteria (totally) do not yield a good fit index with the dialogue and knowledge/understanding criteria. Unlike, the study made a constraint improve the quality of the model, namely the correlation between each of outcome criteria and dialogue and knowledge/understanding factors. Under this condition, the outcome factors yield good fix indexes.

$\mathrm{x}^{2}[375,1]=.43 ;$ Sig. $=.59 ;$ Comparative Fit Index $(\mathrm{CFI})=.74$

Tucker Lewis Index (TLI) $=.85$

root mean square error of approximation $(\mathrm{RMSEA})=.12[.00 ; .15] ;$ Sig. $=.71$

Standardized root mean square residual $(\mathrm{SRMR})=.015$

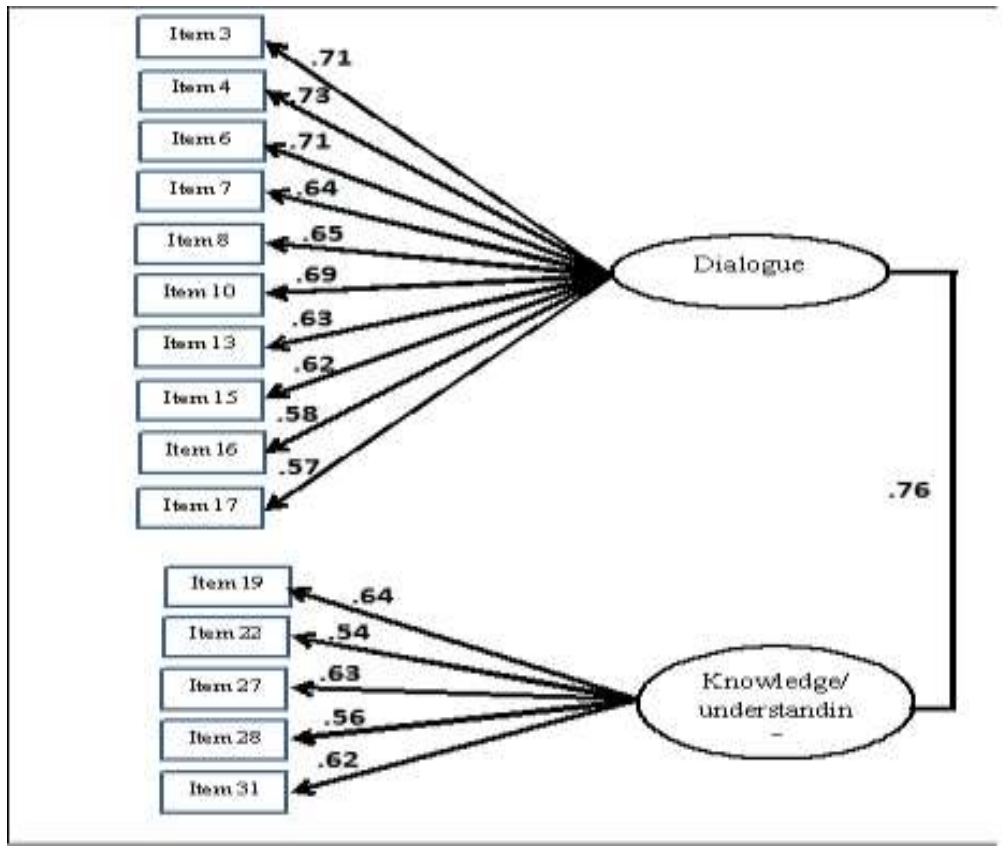

Figure 2: Confirmatory Factor Analysis (CFA) for the dialogue and knowledge/understanding factors 
Table 2: Correlation

\begin{tabular}{|c|c|c|c|c|c|c|c|}
\hline \multicolumn{2}{|c|}{} & ii & iii & iv & v & vi & vii \\
\hline \multirow{3}{*}{$\subsetneq$ ○ } & i & -0.14 & -0.02 & -0.34 & -0.34 & -0.28 & -0.34 \\
\cline { 2 - 8 } & ii & & 0.33 & 0.23 & 0.27 & 0.31 & 0.27 \\
\cline { 2 - 8 } & iii & & & 0.15 & 0.19 & 0.19 & 0.06 \\
\hline \multirow{3}{*}{$\bigcirc$} & iv & & & & 0.68 & 0.56 & 0.49 \\
\cline { 2 - 8 } & $\mathrm{v}$ & & & & & 0.63 & 0.42 \\
\cline { 2 - 8 } & $\mathrm{vi}$ & & & & & & 0.35 \\
\hline
\end{tabular}

i-Place attachments, ii- Concern to preserve cultural identity, iii- The important of CP in the UHC plans, ivDialogue, v- Knowledge, vi- Outcomes, vii- Likelihood of future participation

Table 3: Liner regression (dependent variable is $\mathrm{CP}$ )

\begin{tabular}{cccc}
\hline & Beta $(\beta)$ & $\mathrm{t}$ & Significance \\
\hline 1 & $0 \cdot 23$ & 3.68 & 0.00 \\
2 & $0 \cdot 05$ & 0.68 & 0.50 \\
3 & $0 \cdot 13$ & 2.19 & 0.03 \\
4 & -.16 & -3.28 & 0.00 \\
5 & $0 \cdot 15$ & -3.07 & 0.00 \\
6 & -0.03 & -0.64 & 0.53 \\
\hline
\end{tabular}

1- Dialogue, 2- Knowledge, 3- Outcomes, 4- Place attachments, 5- Concern to preserve cultural identity 6- The important of CP in the UHC plans

In general speaking,the results confirmed that, on one hand, the evaluation criteria of CP (process and outcomes) affect to the participatory behavior of citizens in the Cultural-historic area of Shiraz. Particularly, they showed that both ownerships and inhabitants desire to attend in a group discussion in the form of facilitator agencies when the discussions are: respectful; possess mutual trust; respect to different points of view; equal opportunity to speak; offer common good; reciprocal dialogue; have a feedback communication. More importantly, the results demonstrated that they are active in the CP for UHC initiatives when a dialogue is ongoing as a relational channel between people and local governments. 
On the other hand, the study explored that there is a good correlation between the participatory behaviour of the participants and three independent variables including the place attachment, concern to preserve cultural identity and the importance of $\mathrm{CP}$ in the UHC initiatives. However, these results are generalizable in the part of the process evaluation of $\mathrm{CP}$, while they lack in generalisation in the part of the outcomes because of the specific characteristics of different places.

\subsection{Conclusion}

Since 2002, as the "gatekeepers", lawyers across the world were imposed with a legal duty to report suspicious transactions committed by their clients. However, it is apparent that such obligation is replete with the tensions across many jurisdictions. At one end of the continuum, lawyers in Malaysia the UK and Australia, to some degree, are under such obligation. At the other end, lawyers in Canada, Hong Kong, and New Zealand, who have objected to the duty, are exempted from similar obligations, which consequently led them to be non-compliant with the FATF Recommendations. Despite the imposition of the reporting obligation, legal and practical impediments exist, leading to the lack of compliance with such duty. The APG Mutual Evaluation Report 2007 observed that there was a remarkable lack of reporting by the Malaysian legal professionals of suspicious transactions made by their clients. The notably scarce evidence of the effectiveness of Suspicious Transaction Report system in Malaysia following FATF Recommendation 16 compounded the problem, which consequently led to a rating as partially compliant for Malaysia. Given the forthcoming Mutual Evaluation Report in August this year, such issues should be urgently addressed by the relevant authorities.

\section{References}

Beierle, Thomas C. (1999). Using social goals to evaluate public participation in environmental decisions. Review of Policy Research, 16(3-4), 75-103.

Beierle, Thomas C, \& Cayford, Jerry. (2002). Democracy in practice: Public participation in environmental decisions: Resources for the Future.

Bradbury, Judith A. (1998). Expanding the rationale for analysis and deliberation: looking beyond understanding risk. Human Ecology Review, 5, 42-44.

Charnley, Susan, \& Engelbert, Bruce. (2005). Evaluating public participation in environmental decision-making: EPA's superfund community involvement programme. Journal of Environmental Management, 77(3), 165-182.

Chess, Caron, \& Purcell, Kristen. (1999). Public participation and the environment: Do we know what works? Environmental Science \& Technology, 33(16), 2685-2692.

Dian, Azni Mohd, \& Abdullah, Nuraisyah Chua. (2013). Public participation in heritage sites conservation in Malaysia: issues and challenges. Procedia-Social and Behavioral Sciences, 101, 248-255. 
Edwards, Peter B, Hindmarsh, Richard, Mercer, Holly, Bond, Meghan, \& Rowland, Angela. (2008). A three-stage evaluation of a deliberative event on climate change and transforming energy. Journal of public deliberation, 4(1), 6.

Kong, Lily, \& Yeoh, Brenda SA. (1994). Urban conservation in Singapore: a survey of state policies and popular attitudes. Urban Studies, 31(2), 247-265.

Mannarini, Terri, \& Talò, Cosimo. (2013). Evaluating public participation: instruments and implications for citizen involvement. Community Development, 44(2), 239-256.

Rowe, Gene, \& Frewer, Lynn J. (2000). Public participation methods: A framework for evaluation. Science, technology \& human values, 25(1), 3-29. 